\title{
Investigation of Urban Air Temperature and Humidity Patterns during Extreme Heat Conditions Using Satellite-Derived Data
}

\author{
Leiqiu Hu AND ANDRew J. Monaghan \\ National Center for Atmospheric Research, ${ }^{*}$ Boulder, Colorado \\ NATHANIEL A. BRUNSELL \\ Department of Geography, University of Kansas, Lawrence, Kansas
}

(Manuscript received 17 February 2015, in final form 21 August 2015)

\begin{abstract}
Extreme heat is a leading cause of weather-related human mortality. The urban heat island (UHI) can magnify heat exposure in metropolitan areas. This study investigates the ability of a new MODIS-retrieved near-surface air temperature and humidity dataset to depict urban heat patterns over metropolitan Chicago, Illinois, during June-August 2003-13 under clear-sky conditions. A self-organizing mapping (SOM) technique is used to cluster air temperature data into six predominant patterns. The hottest heat patterns from the SOM analysis are compared with the 11-summer median conditions using the urban heat island curve (UHIC). The UHIC shows the relationship between air temperature (and dewpoint temperature) and urban land-use fraction. It is found that during these hottest events 1) the air temperature and dewpoint temperature over the study area increase most during nighttime, by at least $4 \mathrm{~K}$ relative to the median conditions; 2 ) the urban-rural temperature/humidity gradient is decreased as a result of larger temperature and humidity increases over the areas with greater vegetation fraction than over those with greater urban fraction; and 3) heat patterns grow more rapidly leading up to the events, followed by a slower return to normal conditions afterward. This research provides an alternate way to investigate the spatiotemporal characteristics of the UHI, using a satellite remote sensing perspective on air temperature and humidity. The technique has potential to be applied to cities globally and provides a climatological perspective on extreme heat that complements the many case studies of individual events.
\end{abstract}

\section{Introduction}

More than $50 \%$ of the global population lives in urban areas (World Health Organization 2010), which cover less than $0.5 \%$ of the world's total land area (Schneider et al. 2009). The proportion of persons living in urban areas is likely to grow in the future (Cohen 2003). The urban environment is a complex system, involving concentrated human activities and integrated ecosystem vulnerabilities. Consequently, public health and living conditions are growing concerns in urban areas, especially given

* The National Center for Atmospheric Research is sponsored by the National Science Foundation.

Corresponding author address: Leiqiu Hu, Research Applications Laboratory, National Center for Atmospheric Research, P.O. Box 3000, Boulder, CO 80307-3000.

E-mail: leiqiu@ucar.edu increasing trends toward urbanization, particularly in developing countries (Cohen 2006).

Extreme heat is a leading cause of weather-related human mortality (Borden and Cutter 2008; Kalkstein and Greene 1997; Basu and Samet 2002; O'Neill and Ebi 2009; Peng et al. 2011). For example, more than 3000 reported deaths were related to excessive heat exposure during 1999-2003 in the United States (Centers for Disease Control 2006). The Chicago (Illinois) heat wave in 1995 was responsible for more than 700 heat-related deaths (Whitman et al. 1997; Semenza et al. 1996), while the 2003 heat waves in Europe contributed to over 70000 deaths (Robine et al. 2008). Anthropogenic climate change is likely to amplify extreme heat events in cities (Barriopedro et al. 2011; McCarthy et al. 2010); future projections suggest more frequent, intense, and longer heat waves (Meehl and Tebaldi 2004), which may increase mortality in cities (McGeehin and Mirabelli 2001; O'Neill and Ebi 2009; Peng et al. 2011; Patz et al. 2005). 
The urban heat island (UHI; Oke 1982) is a common phenomenon in which cities exhibit higher temperatures than their adjacent rural surroundings. It is attributed to the progressive modification of land surface materials and structures as well as intensive human activities (Rizwan et al. 2008). The UHI effect can amplify heat waves (Livezey and Tinker 1996) and air pollution (Sarrat et al. 2006), elevating the risk for health problems among urbanites, especially during summer. It is critical to understand the behavior of the UHI during extreme heat events. Recent studies discuss the interaction between the UHI and heat waves through model simulations (Li and Bou-Zeid 2013) and a network of ground observations (Basara and Basara 2010). Fischer et al. (2012) discussed the impact of climate change on the frequency of extreme heat events and the consequences for urban and rural heat stress. The impact of mitigation strategies, including increasing vegetation coverage and raising the albedos of built surfaces such as roofs, have been simulated for extreme heat conditions (Zhou and Shepherd 2010), with the conclusion that increasing vegetation may be a better choice for reducing extreme heat. However, the spatiotemporal distribution of temperature and humidity across urban and adjacent periurban areas during extreme heat events is not well understood. Moreover, the interaction between the UHI and extreme heat events varies regionally because of differences in the geographic setting, urban morphology, and the large-scale drivers of heat waves. Therefore, methodologies for investigating the UHI that can be readily applied to a variety of different cities are needed.

This study builds on recent research that assessed the accuracy of near-surface air temperature and humidity information derived from Moderate-Resolution Imaging Spectroradiometer (MODIS) atmospheric profiles for UHI studies (Hu and Brunsell 2015). While the use of satellite data for UHI research has limitations (e.g., data are only valid for clear-sky conditions), given that MODIS data have global coverage and span nearly $15 \mathrm{yr}$, there is strong potential to employ MODIS data for climatological studies of UHI characteristics. The purpose of this study is to enhance understanding of spatiotemporal patterns of temperature and humidity across metropolitan Chicago during the most intense extreme heat conditions. We aim to better characterize how surface heterogeneity influences near-surface temperature and humidity over the life cycle of extreme heat events.

\section{Data and methods}

Chicago is one of the largest cities in the United States, with about 9 million people living in a metropolitan area of $28 \times 10^{3} \mathrm{~km}^{2}$. Chicago is located near

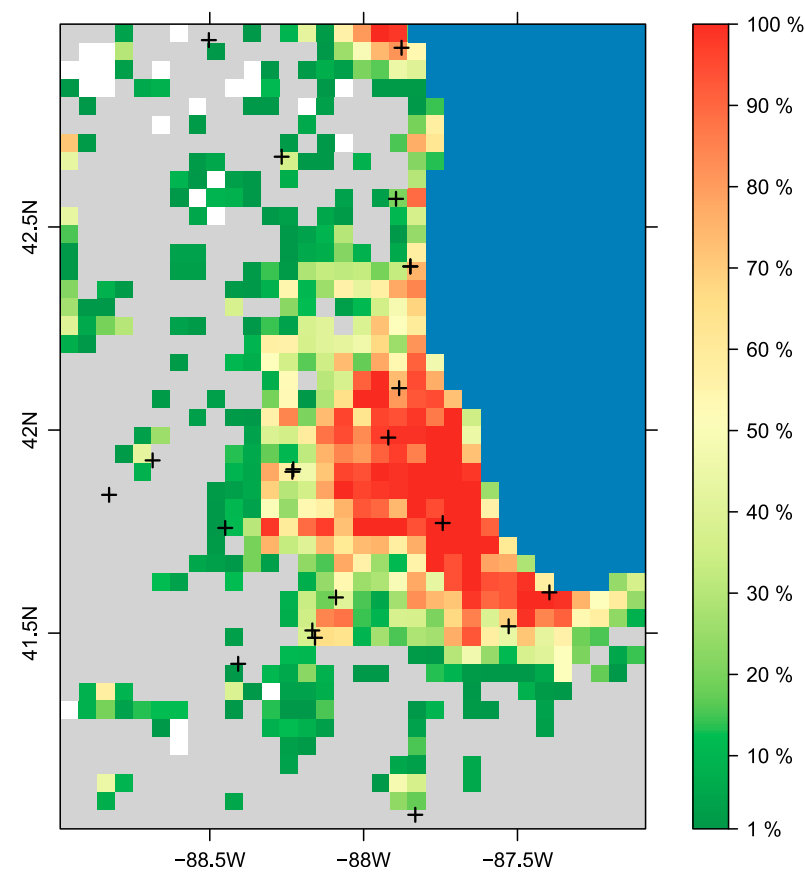

FIG. 1. The urban land-use fractions in 5-km grids estimated from the MODIS MCD12Q1 data in 2012. The gray area indicates fully vegetated pixels at $5-\mathrm{km}$ resolution. The blue area in the domain is Lake Michigan, which is masked for later analysis. The plus symbols indicate the locations of ground weather stations in the study area over land.

Lake Michigan (Fig. 1) and has a humid continental climate consisting of warm-to-hot summers and cold winters with relatively uniform precipitation throughout the year. Chicago has had a number of well-documented heat waves, for example, the July 1995 heat wave, which caused several hundred heat-related deaths (Semenza et al. 1996; Whitman et al. 1997). It is therefore essential to understand the interaction of extreme heat events and Chicago's built environment, which can exacerbate heat stress exposure.

\section{a. Remotely sensed and ground-based observational data}

We used near-surface temperature and humidity fields from the MODIS atmospheric profile product (MOD07_L2 for Terra and MYD07_L2 for Aqua) at $5-\mathrm{km}$ resolution over Greater Chicago during summers (June-August) from 2003 to 2013 (Hu and Brunsell 2015). MODIS is aboard NASA's Terra and Aqua satellites, and has a twice-daily overpass frequency for each satellite. The median local standard times of the four satellite overpasses are approximately 0130 (Aquanight), 1030 (Terra-day), 1230 (Aqua-day) and 2130 (Terra-night). MODIS atmospheric profiles are retrieved from multiple infrared bands of MODIS 


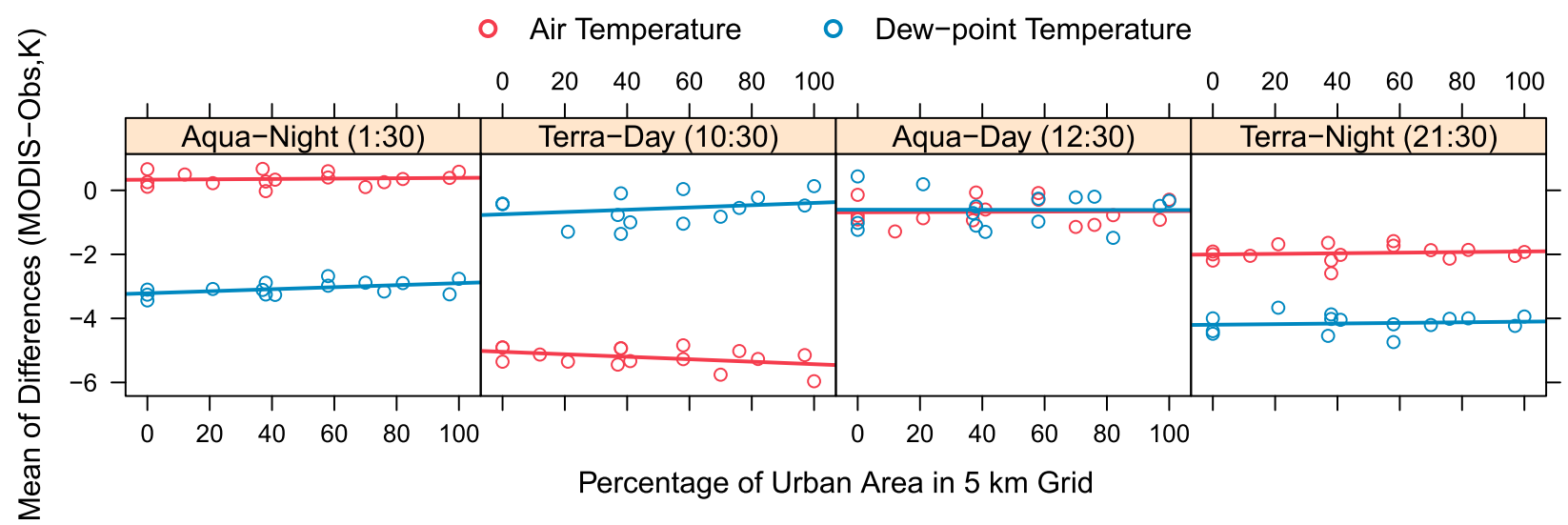

FIG. 2. The mean biases of MODIS retrievals for air temperature (red) and dewpoint temperature (blue) in comparison with corresponding ground observations in pixels containing weather stations. The results are plotted as a function of urban land-use fraction and are shown for each of the four satellite overpasses. The colored lines represent the linear regression of the bias vs urban land-use fraction.

through a statistical-regression-based retrieval process (Seemann et al. 2003, 2006; Borbas et al. 2011). The near-surface atmospheric temperature and humidity are extrapolated from MODIS atmospheric profiles to the surface level using the hydrostatic approximation. More details concerning data preparation and processing can be found in $\mathrm{Hu}$ and Brunsell (2015). Only clear-sky data are used because infrared channels cannot detect the surface through clouds.

According to $\mathrm{Hu}$ and Brunsell (2015), the nearsurface air temperature from MODIS atmospheric profiles is representative of the lower upper boundary layer (UBL); however, the effects of the underlying urban morphology are not explicitly accounted for because the $5-\mathrm{km}$ footprint is too coarse to resolve individual features such as buildings. Since the surface, urban canopy layer, and UBL UHIs are linked but governed by different physical mechanisms, leading to diverse diurnal behaviors (Oke 1995), the results within this study should be interpreted carefully.

The MODIS yearly land-cover product (MCD12Q1) for 2003-12 at $500 \mathrm{~m}$ is used to examine the impact of land-cover types on the surface temperatures. No landcover data were available for 2013 at the time of the analysis, so 2012 land-cover data were applied to the 2013 analysis. Figure 1 illustrates the spatial distribution of urban land-use fraction in every $5-\mathrm{km}$ grid cell over the study area in 2012. The urban land-use fraction at $5-\mathrm{km}$ resolution is aggregated from MODIS land-cover data from $500 \mathrm{~m}$ at an accuracy of $1 \%$ for each land-cover type in each $5-\mathrm{km}$ grid.

Local weather station observations were downloaded from the Integrated Surface Global Hourly dataset via the National Climatic Data Center (NOAA/NCDC 2001). The observations are used for validation and analyses. Quality-controlled observations within $1 \mathrm{~h}$ of satellite overpass time are used. The locations of the 20 weather stations used are shown in Fig. 1.

\section{b. Bias correction}

$\mathrm{Hu}$ and Brunsell (2015) found that the MODISretrieved air and dewpoint temperatures were generally underestimated for the four satellite overpasses when compared with ground observations. Figure 2 illustrates the mean of differences between the MODIS-derived temperature and the weather station observations, categorized by urban land-use fraction from $0 \%$ to $100 \%$. The biases for each weather station are spatially consistent across Chicago regardless of how large the urban land-use fraction is, as evidenced by the small slopes of the lines (all <0.004) in Fig. 2. This indicates that the maximum possible impact of a bias due to the land-cover heterogeneity is smaller than $0.4 \mathrm{~K}$. Similar bias patterns were found in Toronto and Chicago ( $\mathrm{Hu}$ and Brunsell 2015). The dissimilar magnitudes of mean biases among the four satellite overpasses likely result from the existence of biases from the modeled synthetic radiance with respect to the MODIS-measured radiance in the MODIS atmospheric sounding retrieval algorithms (Seemann et al. 2006; Borbas et al. 2005). The landcover-independent bias in Fig. 2 allows us to use the mean difference calculated from MODIS for each satellite overpass and the corresponding observations from all the weather stations (regardless of urban land-use fraction) to effectively and efficiently correct the MODIS bias. The values of the root-mean-square error (RMSE) before and after bias correction are shown in Fig. 3. In general, MODIS nighttime data are more accurate, and the RMSEs after correction are about $3 \mathrm{~K}$ or less. A spatial-scale mismatch existing between the 5-km 

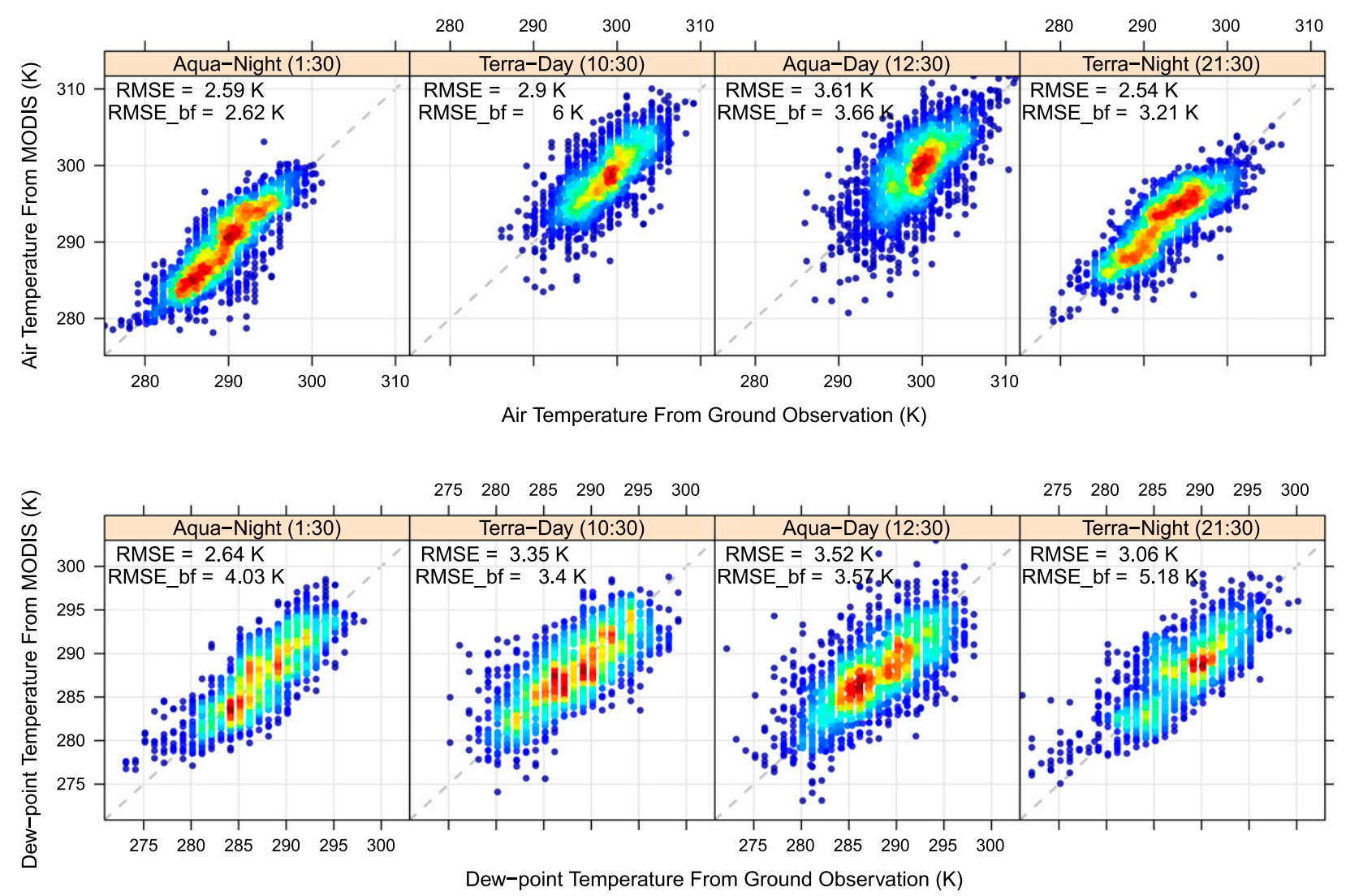

FIG. 3. Density scatterplots of near-surface (top) air temperature and (bottom) dewpoint temperature from MODIS and ground observations after the mean difference adjustments for each satellite overpass. The RMSEs after and before correction are labeled as RMSE and RMSE_bf, respectively.

footprint of the MODIS retrievals and a given point-based ground observation within the footprint, as well as the observing time gaps (less than $1 \mathrm{~h}$ ) between MODIS and weather stations, contribute to the instant RMSEs shown in Fig. 3, and it is not possible to remove these effects from the RMSE calculation. The magnitude of the RMSEs is relatively large compared to the magnitude of UHI, but our analyses are generally based on the temporally aggregated results, which likely significantly decrease the impact of these errors on quantifying the spatial variability of temperatures across the study area. The results regarding the urban-rural contrast should be well represented by the methodology adopted by this study.

\section{c. Identifying heat patterns in space and time}

We hypothesize that the spatial patterns of temperature and moisture in urban areas are different during extreme heat events than during normal summer conditions. The distinct thermal properties of urban and rural surfaces may result in different temperature responses to heat waves than to "normal" conditions, especially considering that the surface moisture distribution-which significantly modulates the partitioning of latent heat fluxes and therefore temperature-may be substantially altered across the metropolitan region during heat waves. Taking advantage of the comprehensive spatial coverage provided by MODIS, we tested this hypothesis by applying a self-organizing map (SOM) technique (Kohonen 1990) to the air temperature data. SOMs are often used to identify distinct spatial patterns in geophysical data in an unsupervised fashion. We categorized each overpass from the 11-yr summertime air temperature record into the six predominant SOM classes (i.e., patterns) and sorted the results from the hottest class (class 1) to the coolest class (class 6). We chose the optimal number of SOM classes to retain through a trialand-error process. We tested SOM classes with four, six, and nine nodes and found that using six optimized the balance between having a sufficient number of samples for the class containing the hottest clear-sky days/nights and having distinguishable patterns among classes. The areas covered by Lake Michigan were masked to decrease the impact of heat patterns over water, which largely differs from land surfaces. Images having extensive cloud 
coverage mask the underlying urban surface temperature patterns; therefore, images with $>27 \%$ of missing data over land were excluded from the SOM training. Landatmosphere interaction plays an important role in describing the spatial variation of heat distribution via both temperature and humidity (Fischer et al. 2007). To assess this interaction and covariation between air temperature and humidity over metropolitan Chicago, the humidity information from MODIS, in the form of dewpoint temperature, was assigned to six classes according to the SOM results for air temperature. For example, if the air temperature image for the Aqua daytime overpass on 6 July 2011 was categorized into class 3 by the SOM, the corresponding dewpoint temperature from the same overpass and day was sorted into class 3 as well.

We used SOMs to cluster the heat patterns instead of directly utilizing ground observations from weather stations, because the measurements from a handful of locations are inadequate to distinguish heat patterns. We tested the temporal consistency between SOM class 1 (the hottest class) and the corresponding observations from Chicago O'Hare International Airport (WMO site code: 725300) at the same quantile of class 1 in all trained data. A temporal agreement was found $58 \%-$ $76 \%$ of the time, depending on the satellite overpass time. However, the consistency varies substantially among the 20 weather stations across the study area of Chicago, likely because of station-specific factors such as the length of the station's record, and the microclimate and location of the site. As a result, it is difficult to consistently categorize "hottest days/nights" across Greater Chicago based on one or more weather stations. Furthermore, the criteria to identify the hottest patterns are not universal for each city because of their microclimatic dissimilarity, potentially leading to incomparability among cities and for different times of a day.

To quantify the influence of urban land use on temperature and moisture at the metropolitan scale, the "urban heat island curve" (UHIC; Hu and Brunsell 2015) was used. The UHIC is designed to explore the spatial relationship between urban atmospheric descriptors (e.g., air temperature and dewpoint temperature) and urban surface properties in terms of urban land-use fraction. We estimated urban fraction in a given $5-\mathrm{km}$ grid cell by aggregating the 500-m MODIS land-cover data (shown in Fig. 1). The temperature and dewpoint temperature data in pixels with $>1 \%$ of water surface area were discarded because of the strong thermal properties of water. We drew the median value of the temperature or dewpoint temperature distribution in each $5 \%$ interval of urban land-use fraction, and then a curve of temperature or dewpoint temperature was constructed as a function of urban land-use fraction.
The $25 \%$ and $75 \%$ quantiles of temperature/dewpoint temperature in each $5 \%$ urban land-use fraction were added to the UHIC to illustrate the variation of results. We added the median temperature of fully vegetated pixels in each UHIC as a reference to quantify the impact from different urban land-use intensities. The UHIC allows one to compare the UHI intensity across space and time and also avoids the dilemma of urbanrural divisions in regions like Chicago that have extensive suburban areas mixed with agricultural and park areas; more details about the methodology can be found in $\mathrm{Hu}$ and Brunsell (2015). The UHIC was applied to each SOM class as well as to the entire dataset to succinctly summarize spatial heat patterns for extremely hot versus normal conditions.

Analyzing the temporal distribution of the SOM heat patterns over the 11 summers is helpful for understanding the general evolution of extreme heat events. To characterize the temporal patterns for the hottest SOM class, the dates of SOM class 1 were identified for each satellite overpass. Then, the frequency of each class for the consecutive four days preceding and following each SOM class 1 event was calculated. Moreover, we explored the correlation between each class 1 event from a given satellite overpass with the other three overpasses, which aids in understanding the probability of hottest patterns occurring over a consecutive period, and whether the heat pattern in a given satellite overpass may be predictive of heat patterns in subsequent overpasses.

\section{Results and discussion}

\section{a. Spatial analysis of urban heat patterns}

The resulting six patterns identified by SOM classification indicate different levels of summertime heat, from the hottest (class 1) to the coolest (class 6). The results for Aqua daytime (1230) and nighttime passes (0130) are illustrated in Figs. 4a and 4b, respectively. The patterns for Terra overpasses are similar. The image number as well as the mean air and dewpoint temperature for each SOM class are illustrated in Fig. 4c. Generally, the majority of days and nights belong to classes 2-5. Class 1 accounts for $11.2 \%$ (Aqua-night), 12.7\% (Terra-day), 5.6\% (Aqua-day), and 6.3\% (Terra-night) of the total SOM-trained data. The total number of clear-sky images available for each overpass time ranges from 519 to 526 , which is about half of the total possible satellite overpasses in 11 summers (1012 days). The daytime (nighttime) mean air temperature difference from one class to the next is about $2.3 \mathrm{~K}(2.9 \mathrm{~K})$. It is noteworthy that the temperature difference between 
(a) Aqua-Day
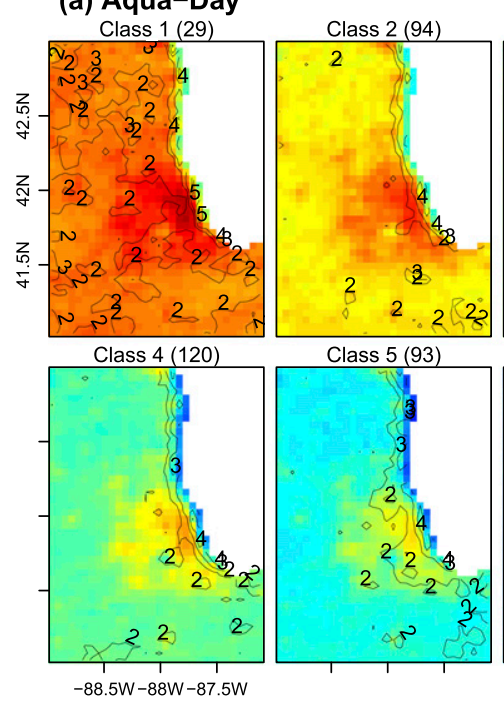

(c)

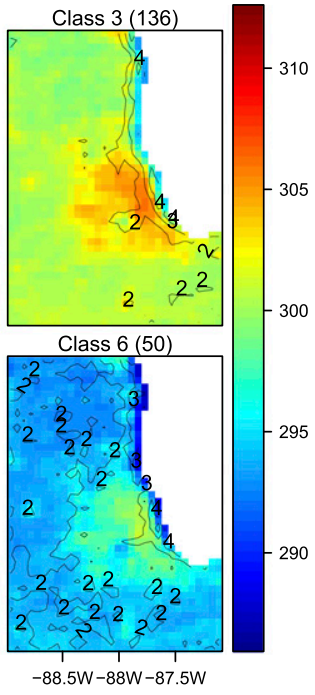

\section{(b) Aqua-Night}

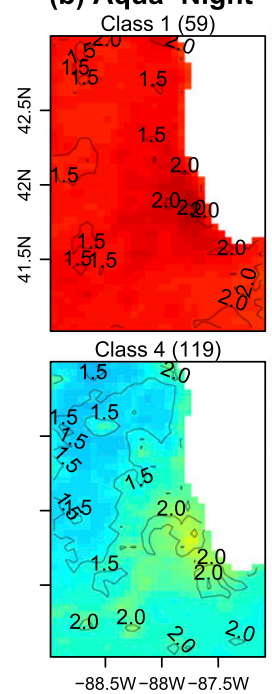

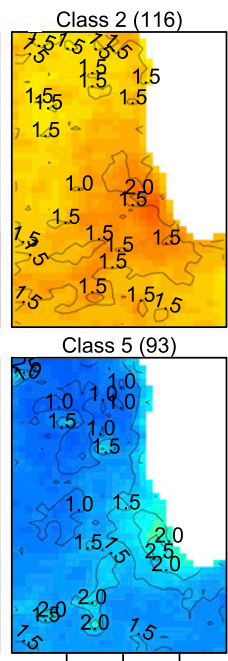

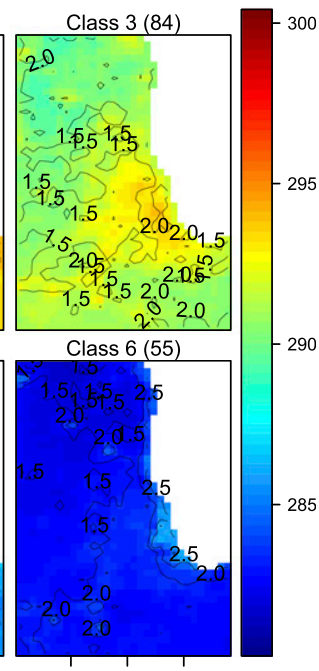

$-88.5 W-88 W-87.5 W$ 300 5 85

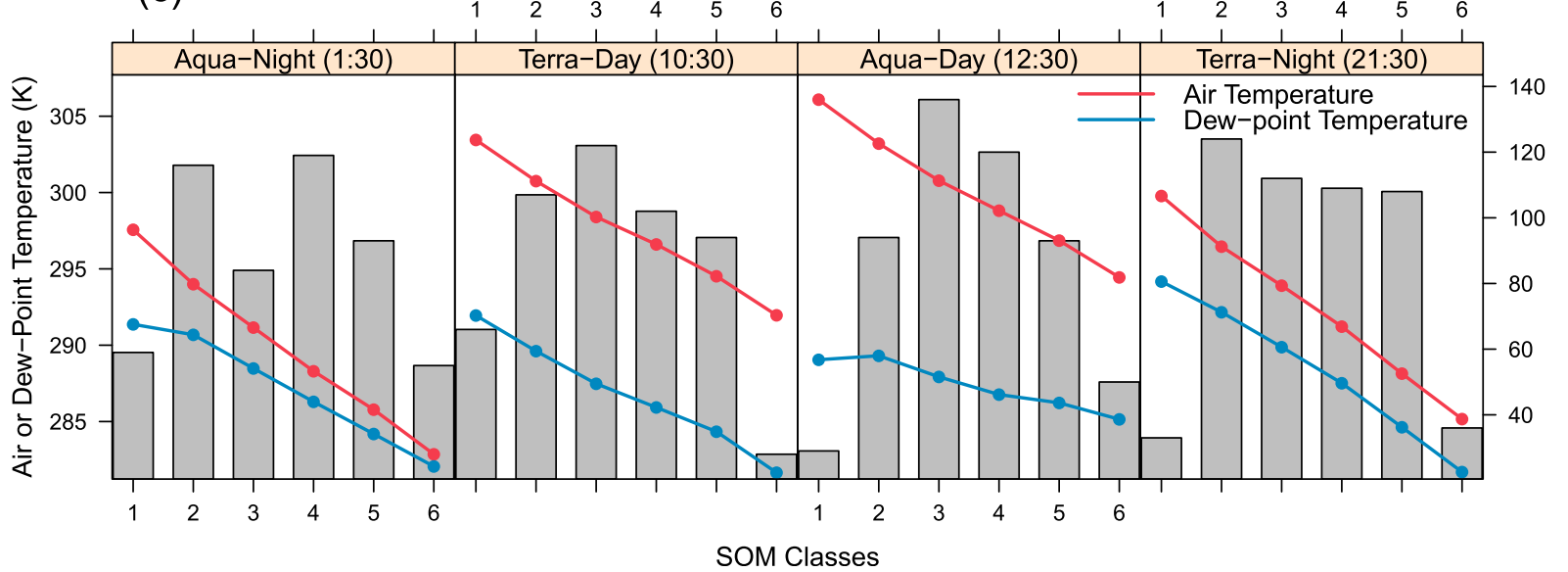

FIG. 4. The averaged air temperature (K) maps of the six SOM classes at the (a) Aqua-day and (b) Aqua-night satellite overpasses. The contour lines show the corresponding standard deviation of temperature in each SOM class. The number of days that belong to each class is labeled in the parentheses. (c) The number of images (gray bar plot; right $y$ axis) and the mean air and dewpoint temperatures (red and blue lines, respectively; left $y$ axis) for each SOM class.

class 1 and 2 is the largest when compared with the differences between all other consecutive classes. The class 1 heat pattern during the daytime illustrates relatively larger spatial variations among the hottest days compared to other classes. In contrast, the warmest clear-sky nights (class 1 for nighttime) exhibit comparatively more spatial homogeneity.

To better understand the magnitude of the UHI effect for the hottest summer conditions, the UHICs of air temperature and dewpoint temperature in classes 1 and 2 and the UHIC of all SOM-trained data are estimated and shown in Fig. 5. The dashed lines describe the median temperature of fully vegetated pixels in the study area (gray areas in Fig. 1), allowing the background temperature and urban-influenced temperature for the same weather conditions to be compared. Because of urban sprawl, the median temperatures of pixels with low urban land-use fractions $(1 \%-5 \%)$ and fully vegetated pixels are nearly identical across the four satellite overpasses. Therefore, the temperature range of a given UHIC can represent the maxima of the UHI magnitude across space for each satellite overpass.

For air temperature (the first row of Fig. 5), the overall shapes and variability of the UHICs during the hottest daytime conditions are generally consistent with those under normal summer conditions in terms of how increasingly urbanized surfaces influence temperatures. However, the slope and range of temperature is smaller for class 1 (the hottest summer class). The urbanrural temperature range for class 1 over the Chicago 


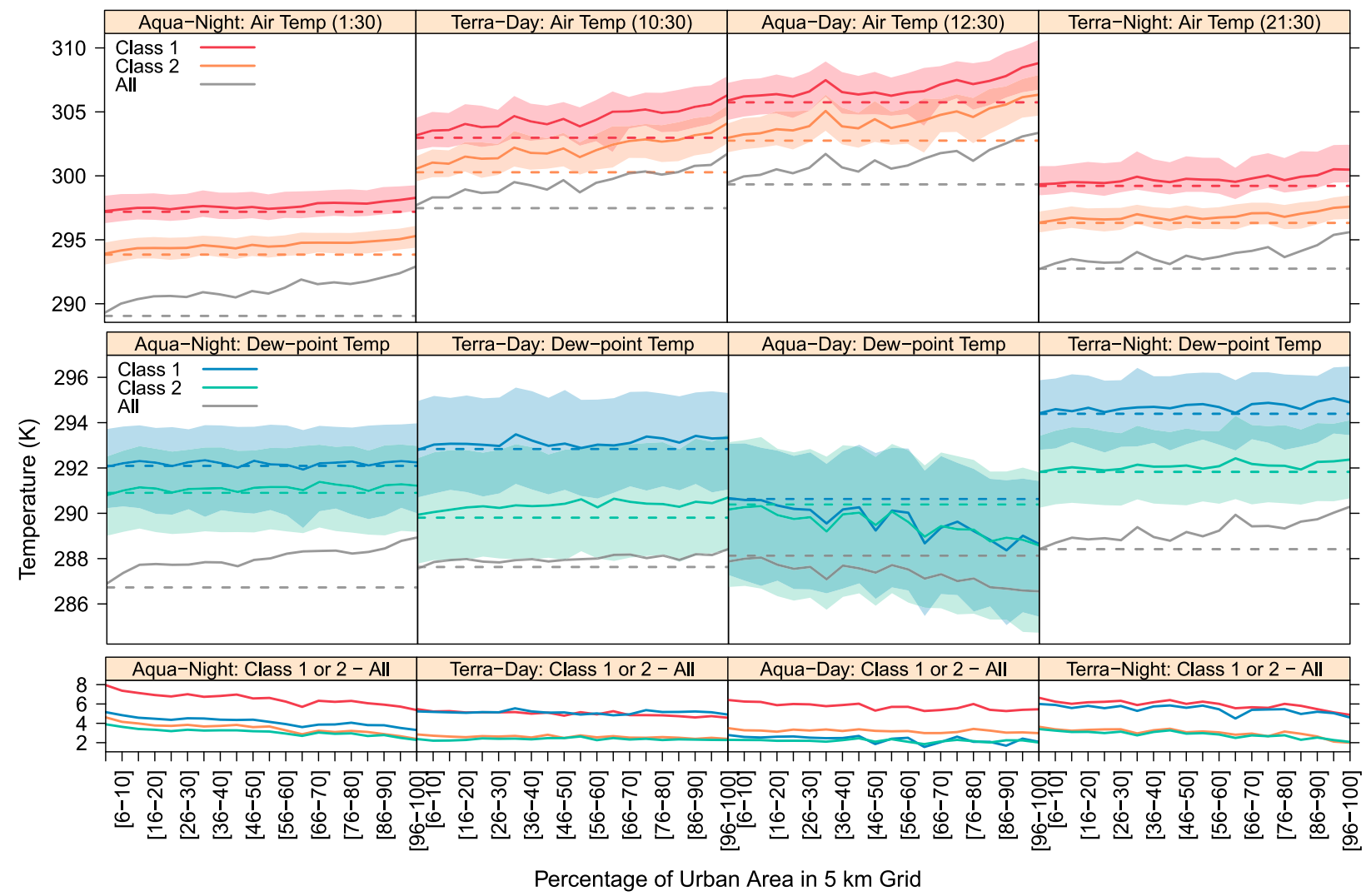

FIG. 5. The UHICs constructed from SOM classes 1-2 (red and orange for air temperature, and blue and green for dewpoint temperature) and all SOM-trained data (gray) for MODIS (top) air temperature and (middle) dewpoint temperature at four satellite overpasses. The solid lines represent the UHICs, and dashed lines show the median temperatures of fully vegetated pixels in the corresponding classes. The color-shaded belt defines the $25 \%$ and $75 \%$ quantiles of temperature distribution in each urban land-use-fraction group. (bottom) The temperature differences between UHIC in class 1 (or class 2) and one constructed from all trained data; red and orange represent the air temperature, and blue and green represent the dewpoint temperature.

metropolitan area is about 3.2 and $2.7 \mathrm{~K}$ for the Terra and Aqua daytime overpasses, respectively, a decrease of at least $1 \mathrm{~K}$ relative to the median 11 -summer conditions, which are depicted as gray solid lines in Fig. 5. These results are consistent with the findings for the 2003 heat wave in Paris with a significant enhanced daytime rural land surface temperature (Dousset et al. 2011). The response of nighttime air temperature to the urban surface influence under the hottest and median summer conditions notably differs from daytime conditions, in both UHIC variation and the temperature range from the least urbanized to the most urbanized areas. The urban-rural temperature range estimated from class 1 UHICs decreases to $1.1 \mathrm{~K}$ for Terra and Aqua nighttime overpasses. As with the daytime conditions, these values are smaller than the median nighttime urban-rural range of up to $2.7 \mathrm{~K}$ (Terra-night) and $3.7 \mathrm{~K}$ (Aqua-night). Therefore, temperature variability is lowest across the metropolitan region during the hottest days and nights.
The UHICs of dewpoint temperature are also shown in Fig. 5 (second row) because of their important role in heat stress during extremely hot weather conditions. The ubiquitous higher dewpoint temperatures occur during the hottest conditions, in agreement with findings for individual heat waves such as the July 1995 event in Chicago (Kunkel et al. 1996; Livezey and Tinker 1996), indicating that higher humidity may particularly exacerbate heat stress during heat waves. This pattern in Chicago during the heat waves in a recent decade was found highly correlated to the anomalies of regional precipitation prior to the heat event as well as the change of agricultural practices (Changnon et al. 2003). Interestingly, within each class a strong urban moisture deficit (relative to rural areas) occurs for the afternoon (Aqua-day) overpass, when strong afternoon convective activity is often present. The strong convection may accelerate the dissipation of water vapor within the planetary boundary layer. Additionally, the more impervious urban surfaces may promote runoff and inhibit 
afternoon evaporation (because of the lack of a moisture source) compared to rural areas (Champollion et al. 2009). The hottest conditions illustrate a stronger spatial variation of humidity. The similar patterns of UHIC for class 1 and class 2 highlight the strong moisture limitations that occur during the hottest afternoons. To explain, despite large differences in dewpoint temperatures between class 1 and class 2 during the morning (Terra-day), by afternoon the dewpoint temperature differences between the two classes become negligible (Aqua-day). This may be partly due to vegetation controls on evapotranspiration, which is supported by the fact that afternoon dewpoint temperatures are lowest over the most urbanized (least vegetated) surfaces.

The nocturnal urban moisture excess (UME) is present under the median summer conditions, which may result from slightly higher urban temperatures that encourage evaporation and inhibit condensation well into the night, and/or additional water vapor sources from anthropogenic emissions, etc. (Champollion et al. 2009; Kuttler et al. 2007; Richards 2005; Mayer et al. 2003). Conversely, and similar to air temperature, the urbanrural range of the nocturnal humidity is comparatively lower during the hottest conditions, showing a more homogeneous spatial pattern. Unfortunately, the hottest summer nights have a combination of higher temperature and humidity relative to median conditions, and with less spatial variability over metropolitan Chicago. In the city where the use of air conditioning is widespread, especially for the elderly and the poor (Klinenberg 2002), these conditions may exacerbate heat stress.

As urban land-use fraction increases, the air and dewpoint temperature anomalies between class 1 and all SOM-trained data are decreasing, as shown in the third row of Fig. 5. The magnitude of decreasing trends varies for different satellite overpasses, and nighttime shows a larger spatial change in general. For instance, the Aquanight air temperature anomalies are up to $7.9 \mathrm{~K}$ where the urban land-use fractions are low $(1 \%-5 \%)$, while the anomalies decline to $5.3 \mathrm{~K}$ for intensively urbanized areas. The trends of dewpoint temperature anomalies are similar to air temperature. In other words, heat events in Chicago generally result in smaller urban-rural temperature-moisture gradients as a result of greater temperature and humidity increases over vegetated-rural areas, particularly during nighttime. It is notable that the UHIC is constructed from the entire or the part (SOM class 1 or 2) of SOM-trained dataset, which integrates the influence from land-cover changes during these $11 \mathrm{yr}$; this impact is not separated from the analysis.

Air temperature and dewpoint temperature over both rural and urban areas increase during extreme heat events, but the magnitude of the increase is higher for the more vegetated rural areas, which reduces the humidity gradient between rural and urban regions. Vegetation in the rural areas and nonurban areas within the urban environment (e.g., parks) generally exhibits enhanced latent heat fluxes compared to urban surfaces because of the higher moisture content of vegetated surfaces, which means there is less energy available for sensible heating. However, during heat waves high evapotranspiration rates over vegetated surfaces may deplete soil moisture more quickly than under normal conditions, which would free up additional energy for sensible heating and lead to differentially large warming over vegetated surfaces relative to urban surfaces. Moreover, the UHI is also sensitive to the spatial variability of humidity, where water vapor provides a radiative force that probably influences the UHI development (Lee 1991; Holmer and Eliasson 1999; Mayer et al. 2003). The relatively homogeneous distribution of high nighttime water vapor in the atmosphere during heat events drives a more equal spatial distribution of downward longwave irradiation (Mayer et al. 2003; Eliasson and Holmer 1990), which further reduces the urban-rural temperature differences in contrast to the strong nocturnal UME during the median summer nights with a strong UHI.

The principal cause of extreme heat events is generally linked with large-scale meteorological forcing, with strong high pressure systems often being associated with hot and humid conditions in Chicago (Livezey and Tinker 1996). Local and microclimatic urban effects contribute to the unique spatial patterns observed during these events (Kunkel et al. 1996). When prolonged large-scale forcing conditions (e.g., atmospheric blocking) leads to drought, extreme heat can be exacerbated because evapotranspiration is more likely to be limited because of lack of moisture, so most energy is partitioned into sensible heating (Cornic and Massacci 1996). This is one possible reason for the decreased spatial heterogeneity of air temperature during the hottest days, since changes from latent toward sensible heating will be particularly large over (the generally moister) vegetated/rural surfaces relative to urban surfaces. To test this hypothesis, we summarized the U.S. drought category information associated with each SOM classification for the Aqua-day overpass, in terms of percentage of surface area within each of four rural watersheds surrounding the metro area that fall into five different levels of drought conditions. The results are shown in Fig. 6. When compared with the other classes, SOM classes 1 and 2 clearly have more surface area within more severe drought categories over these rural areas. The total drought areas (D0-D4) sum up to about $60 \%$ of the area within each watershed during the SOM 


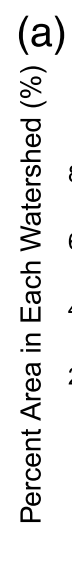

(b)

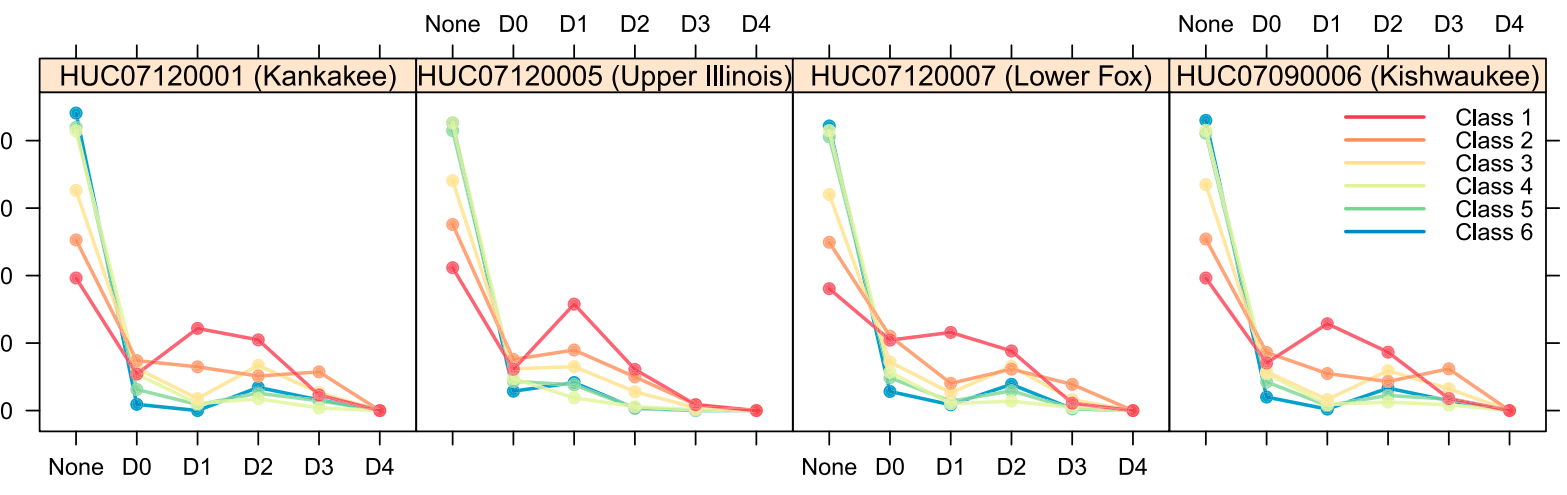

U.S. Drought Monitor Categories

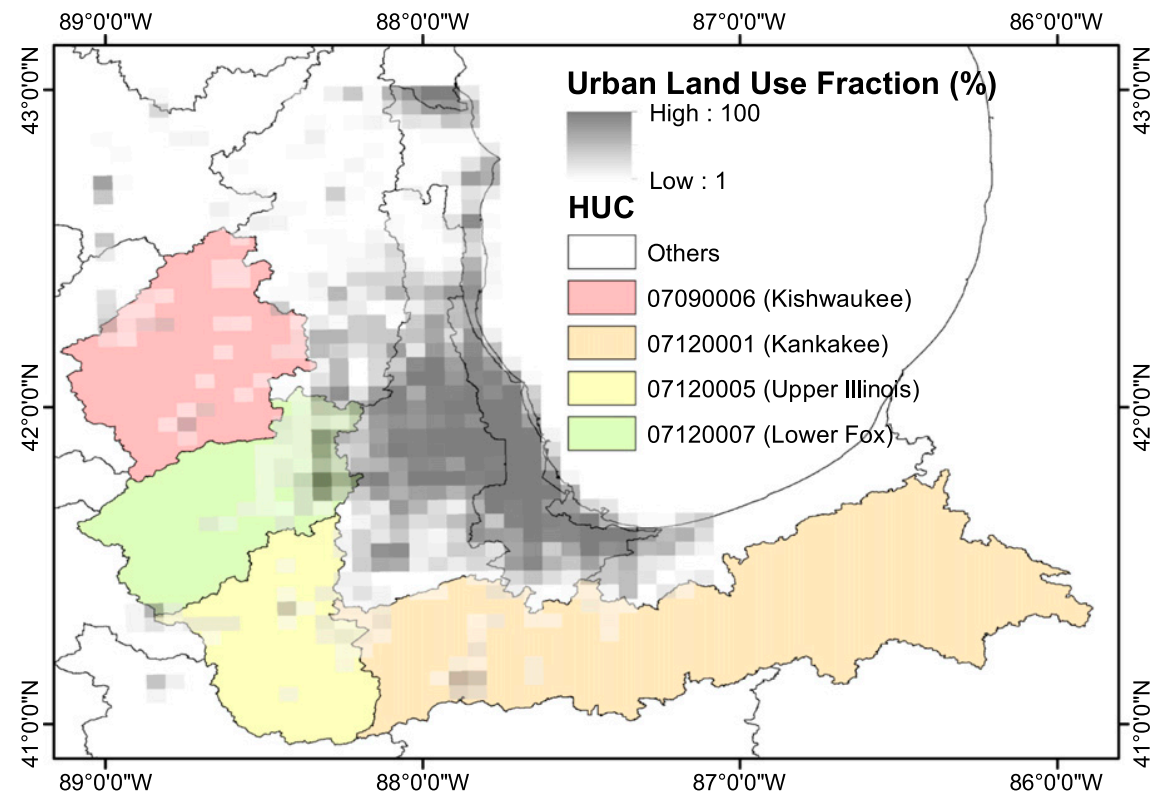

FIG. 6. (a) Percentage area within four rural watersheds surrounding metropolitan Chicago that are within each of the five drought monitor categories for each SOM class belonging to the Aqua-day (1230) overpass during summers from 2003 to 2013. The drought monitor categories are abnormally dry (D0), moderate drought (D1), severe drought (D2), extreme drought (D3), and exceptional drought (D4). The hydrologic unit code (HUC) identifies the watershed. (b) Map showing the four rural watersheds surrounding Chicago mentioned in (a) that were used to assess drought conditions for different SOM classes. The grayscale map shows the urban land-use fraction.

class 1 events, which would mean more sensible heating (and higher temperatures) would occur in rural areas during extreme heat events.

Another reason is that hot and clear weather conditions encourage convection because of intensive surface heating during the daytime, thereby promoting more horizontal mixing near the surface (urban-rural advection), leading to more homogeneous heat distributions (Haeger-Eugensson and Holmer 1999). Indeed, wind speeds observed at Chicago O'Hare International Airport are higher by $0.56-1.36 \mathrm{~km} \mathrm{~h}^{-1}$ during the hottest heat patterns (class 1) for all four daily satellite overpasses when compared with median summer conditions, particularly in the afternoon (Aqua-day) and after midnight (Aqua-night) for which wind speeds were statistically significantly higher $(p<0.05)$. Wind directions are different as well during the hottest events. The predominant wind direction during class 1 events is southwesterly at all times of day, which has been linked to an amplified ridge in the western and central United States (Livezey and Tinker 1996). However, during median conditions, which are usually associated with weak large-scale forcing, the winds are northeasterly during daytime/evening and southwesterly at night, consistent with the diurnal lake-land breeze cycle. Given the cooling effect of lake breezes on temperatures 


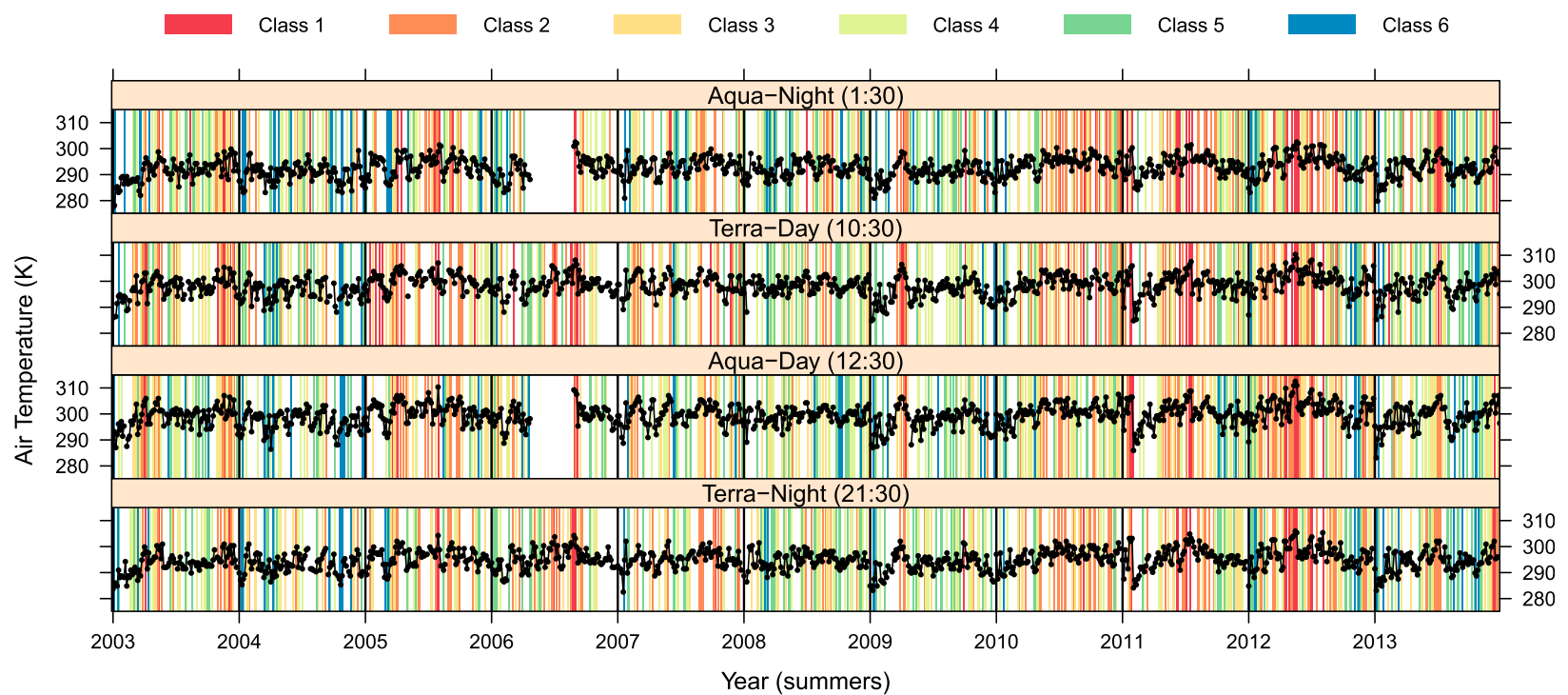

FIG. 7. The time series of SOM classes (colored vertical lines) and ground temperature observations (black points/lines) at Chicago O'Hare International Airport (WMO site code: 725300) during summers from 2003 to 2013. The white areas indicate days on which no class was assigned, which may be due to the presence of a large amount of clouds or data unavailability (e.g., in July 2006 Aqua overpasses).

over land, the diminished lake-breeze circulation may exert a positive feedback that exacerbates extreme heat events over Chicago. In summary, weather systems can efficiently decrease the heat spatial heterogeneity during the hottest events by increasing turbulence and ventilation (Runnalls and Oke 2000).

This study uses a unique dataset and methodologies that lead to somewhat different conclusions than those of other research on the interaction between UHI and heat waves or extreme heat events. For example, Li and Bou-Zeid (2013) found that the UHI (i.e., the ruralurban temperature contrast) is amplified during heat waves in the Baltimore, Maryland-Washington, D.C., region, based on modeling and observations from two ground sites. Since the MODIS-based air temperature and humidity information more likely depicts the characteristics of UBL UHIs during the extreme heat events, the different nature of UHI types may result in some dissimilarities. Other than that, our study comprehensively integrates spatial information rather than assessing paired information from urban and rural points, and shows a larger UHI effect during daytime than nighttime for the hottest conditions, although the overall UHI (rural-urban temperature contrast) is diminished. As Li and Bou-Zeid (2013) mention, somewhat different results are obtained when calculating the UHI from spatially averaged versus point-based data; for example, the daytime UHI is slightly stronger than the nighttime UHI during and after the heat waves when using spatially averaged results. Another major difference is that $\mathrm{Li}$ and Bou-Zeid (2013) focus on one multiday heat event, whereas our results are for all single- and multiday clear-sky events over 11 summers. A strong surface moisture deficit and low wind speeds are major causes of the extreme heat according to Li and Bou-Zeid (2013). However, this differs from our general findings for Chicago, where a strong surface moisture deficit was observed during the early afternoon for class 1 events, but at all other times of day conditions are more humid than for median conditions. Moreover, the near-surface wind speed was higher in class 1 . In general, our results do show that heat stress is amplified by the urban built environment during the hottest events, but the urban-rural contrast (the UHI) is reduced, specifically at night. We conclude that this departure from the results of Li and Bou-Zeid (2013) is likely due to differences in the types of UHI, geolocation, methodology, and time scales of analysis.

\section{b. Temporal characteristics of urban heat patterns}

To identify the temporal distribution of the hottest days and nights, we plotted a time series of SOM classes over the 11-yr period for each overpass time (Fig. 7). The ground observations within $\pm 1 \mathrm{~h}$ of satellite overpasses at Chicago O'Hare International Airport are also illustrated. Although the heat patterns were assessed independently for individual satellite overpasses, the four snapshots of the diurnal cycle share similar temporal patterns among the SOM classes. The diurnal features of heat patterns in the hottest conditions may help determine the predictability of heat pattern among the different satellite overpasses. 


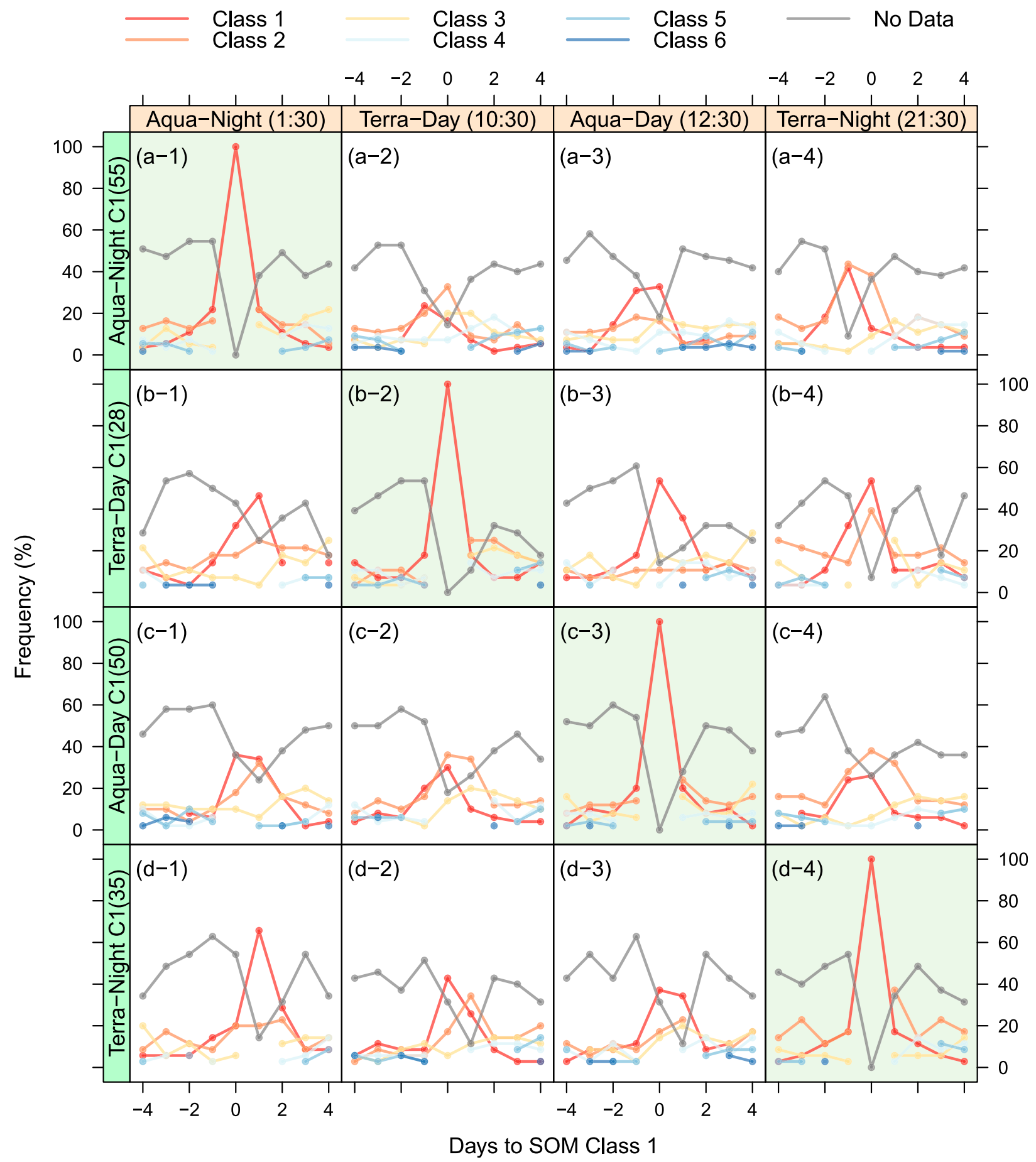

FIG. 8. The normalized occurrences of SOM classes (solid color-coded lines) for the consecutive four days before and after each SOM class 1 event. Each row is calculated conditioned on the SOM class 1 events defined by the satellite overpass indicated in the row header (left strips in green). The number of class 1 events is labeled in the parentheses in the row header. Each column uses the SOM classification for the satellite overpass indicated in the column header, conditioned on the SOM class 1 defined by different satellite overpasses indicated in the rows. The green-shaded panels on the diagonal are the frequency of each SOM class based on the class 1 defined by the same satellite overpass. Aqua-night, Terra-day, Aqua-day, and Terra-night are ordered according to the diurnal cycle starting from 0000, and the median overpass times are labeled in the column headers. Gray lines show the frequency of days/nights that are not classified because of missing data (clouds) for the SOM analysis only. 
The temporal distributions of the six SOM classes for four consecutive days before and after the date of each SOM class 1 (hottest) event are statistically assessed. The normalized occurrences of class 1 and other classes within the 9-day windows of class 1 are illustrated in Fig. 8. The figures on the diagonal of Fig. 8 lattice (green-shaded figures) particularly show the distributions of class types using class 1 defined by the same satellite overpass time. Statistics were computed with a moving window of each 9-day period with the fifth date belonging to the class 1 pattern, so the class 1 curve on the diagonal is symmetrical. These values indicate the probability of occurrence for class 1 patterns on consecutive days. For example, there is approximately a $20 \%$ chance of two consecutive days with the class 1 pattern for all four satellite overpass times. The probability that three days belong to class 1 drops below $10 \%$. Interestingly, in the green-shaded figures, the probability of class 2 (orange lines) after class 1 is higher than that before class 1 (the same is true for class 3 , shown by yellow lines). This result suggests that heat patterns grow more rapidly leading up to the hottest events, followed by a slower return to normal conditions afterward. The fast evolution may be related to the change of large-scale weather conditions, which is beyond the scope of this study. And the extended impact in subsequent days may be attributed to the cumulative storage of heat over the urban built environment. Moreover, plants also require time to recover after heat and/or water stress, so evapotranspiration may be inhibited in the days after an extreme heat event.

The temporal variations for cloudy days ("no data" in Fig. 8) related to the date of class 1 are also informative. Cloudy or partly cloudy conditions occur about $50 \%$ of the time preceding class 1 events, while clouds are less likely in the dates afterward. This pattern is especially strong for daytime. Possibly, the exhaustion of surface moisture during heat events decreases surface water availability for cloud formation after class 1 events.

Also shown in Fig. 8 is the relationship between class 1 events for one satellite overpass and the various SOM patterns for the other three overpass times by each row. For example, the class 1 dates defined by Terra-night overpass (Fig. 8, row d) were used to analyze Aqua-night SOM class distributions (Fig. 8, column 1), and the results are shown in Fig. 8d-1. When these 35 class 1 days were found during Terra-night overpasses ( 0 day, before midnight), as expected, about $60 \%$ of Aqua-night overpasses ( +1 day, after midnight) also are class 1 , and about $20 \%$ are class 2 , and otherwise it is cloudy. In another example, about $60 \%$ of class 1 events occur during early afternoon (Aqua-day, Fig. 8 column 3) when the late morning (Terra-day, Fig. 8 row b) is class 1 (Fig. 8b-3).
Some results summarized from the class distributions in Fig. 8 are 1) the heat patterns during nighttime are closely related to the daytime heat patterns preceding them, and 2) a class 1 pattern during late morning (Terra-day) is followed by a class 1 pattern the following other three times of a given day more than $50 \%$ of the time. In summary, these results suggest there may be some short-term predictive skill for extreme heat events based on patterns observed for previous overpasses, though it is not presently clear whether such information could improve upon forecasts from meteorological models.

\section{Conclusions}

This research provides an alternate way to investigate the temporal and spatial characteristics of the UHI using a satellite remote sensing perspective. By using SOMs for heat pattern classification and the UHIC for quantifying urban land-use impacts on near-surface atmospheric properties, this study concluded that during the hottest events in Chicago, heat stress is intensified by the interaction between both UHI and heat events, particularly during nighttime, with both air temperature and dewpoint temperature over the study area being greater than for median conditions by at least $4 \mathrm{~K}$. Moreover, the urban-rural temperature and humidity gradients are decreased as a result of larger temperature and humidity increases over vegetated/rural surfaces compared to predominantly urban surfaces. A temporal analysis of the heat pattern distributions for clear-sky conditions suggests that heat patterns grow more rapidly leading up to the hottest events, followed by a slower return to normal conditions afterward. Both the dataset and methodology presented here have the potential to be applied to cities globally. This study provides a climatological perspective on extreme heat that complements the many previous case studies of individual events. Better characterization of urban heat patterns will aid decision-makers in mitigating the urban heat island and in preparing for more frequent and intense extreme heat events in the future (Oleson et al. 2015).

The UHIC analysis summarizes the climatological, regionally integrated temperature and moisture spatial patterns for extreme heat events. Urban extreme heat events are the result of complex meteorological and anthropogenically influenced processes acting on multiple scales. These events vary among one another in terms of longevity, frequency, intensity, and causality (Kunkel et al. 1996; Fischer et al. 2007). Clearly, multiple approaches at a variety of temporal and spatial scales are required to fully understand the causality and nature of extreme heat events for a given city. 
This analysis is limited to clear-sky conditions. During daytime, clouds play an important role in determining the UHI magnitude. Clouds modulate the energy budget by blocking or scattering direct solar radiation, and also alter the longwave radiation exchange between the atmosphere and surface. Daytime clouds generally dampen the UHI, especially low clouds (Runnalls and Oke 2000). However, a study in London shows a higher daytime UHI during partially cloudy and cloudy periods in the summer, which is attributed to rainfall (Kolokotroni and Giridharan 2008). The nocturnal UHI is generally larger for clear-sky conditions (Oke et al. 1991; Runnalls and Oke 2000; Kolokotroni and Giridharan 2008). Clouds influence the net longwave radiation budget at the surface, and decrease the urban-rural contrast at night (Runnalls and Oke 2000; Yow 2007).

Increasing the fraction of green space in cities is a widely suggested solution for mitigating the UHI (Zhou and Shepherd 2010). Of relevance, during the hottest events we found the biggest increases of temperature and humidity were for areas with greater vegetation in Chicago. Plants in rural and urban environments experience different levels of water and heat stress as a result of different management strategies, species, and thermal environments, which may elicit differential responses, such as deleterious and/or adaptive changes (Chaves et al. 2002). These details require scrutiny to elucidate under what conditions, and at what scales, vegetation may be beneficial for reducing the UHI.

The MODIS data provide four snapshots of heat patterns over the diurnal cycle. However, explaining the evolution of extreme heat events comprehensively may require data with higher temporal frequency, especially during critical times such as sunrise and sunset. Another limitation is that the methodology for estimating the near-surface temperature and moisture from MODIS atmospheric profiles has a relatively coarse spatial resolution (Hu and Brunsell 2015). Therefore, the temperature and moisture retrievals are representative of the integrated effects of throughout the urban boundary layer. This fact should be considered when interpreting the magnitude of the UHI and when comparing the results with other UHI studies based on ground observations.

Urban remote sensing faces issues related to the anisotropic thermal properties and structures in the urban environment (Voogt and Oke 2003; Lagouarde et al. 2004). Although the nature of air temperature should not be impacted by the sensor view angle, this MODIS dataset is retrieved from zenith angles ranging from $0^{\circ}$ (nadir) to $65^{\circ}$, and it is likely that there is some (uncertain) anisotropic impact. The relatively coarse spatial resolution of the retrievals may dampen this impact. In fact, this is a long-term analysis with samples from many different view angles, which helps to maximize the representativeness in space and time of the anisotropic distributions.

Although there are many challenges associated with urban remote sensing, the techniques and results presented within can contribute to a more comprehensive understanding of the UHI, especially if applied to other cities in a variety of climatic regions. Augmenting MODIS retrievals with atmospheric model simulations may further supplement our understanding of urban climatology and aid in identifying model weaknesses. It is also noteworthy that heat stress indices, which provide better indicators of heat stress than temperature or humidity alone, can be calculated from the air temperature and dewpoint temperature retrievals. Such information may benefit studies aimed at assessing the health impacts of extreme heat.

Acknowledgments. The authors thank Dr. Olga Wilhelmi (NCAR) and the anonymous reviewer for valuable comments on the manuscript. This research was supported in part by NASA Grant NNX10AK79G. The authors also thank NASA for free access to MODIS products. The U.S. Drought Monitor data used in this study is jointly produced by the National Drought Mitigation Center at the University of Nebraska-Lincoln, the U.S. Department of Agriculture, and the National Oceanic and Atmospheric Administration.

\section{REFERENCES}

Barriopedro, D., E. M. Fischer, J. Luterbacher, R. M. Trigo, and R. García-Herrera, 2011: The hot summer of 2010: Redrawing the temperature record map of Europe. Science, 332, 220-224, doi:10.1126/science.1201224.

Basara, J., and H. Basara, 2010: The impact of the urban heat island during an intense heat wave in Oklahoma City. Adv. Meteor., 2010, 230365, doi:10.1155/2010/230365.

Basu, R., and J. Samet, 2002: Relation between elevated ambient temperature and mortality: A review of the epidemiologic evidence. Epidemiol. Rev., 24, 190-202, doi:10.1093/epirev/ mxf007.

Borbas, E., S. W. Seemann, H.-L. Huang, J. Li, and W. P. Menzel, 2005: Global profile training database for satellite regression retrievals with estimates of skin temperature and emissivity. Proc. XIV Int. ATOVS Study Conf., Beijing, China, ITWG, 763-770. [Available online at https://cimss.ssec.wisc.edu/itwg/ itsc/itsc14/proceedings/B32_Borbas.pdf.]

$\_,-$A. Kern, and L. Moy, 2011: MODIS atmospheric profile retrieval. University of Wisconsin-Madison Algorithm Theoretical Basis Doc., 30 pp.

Borden, K. A., and S. L. Cutter, 2008: Spatial patterns of natural hazards mortality in the United States. Int. J. Health Geogr., 7 , 64, doi:10.1186/1476-072X-7-64.

Centers for Disease Control, 2006: Heat-related deaths-United States, 1999-2003. Mortality and Morbidity Weekly Report, 
Vol. 55, CDC, Atlanta, GA, 796-798. [Available online at http://www.cdc.gov/mmwr/preview/mmwrhtml/mm5529a2. htm.]

Champollion, C., P. Drobinski, M. Haeffelin, O. Bock, J. Tarniewicz, M. N. Bouin, and R. Vautard, 2009: Water vapour variability induced by urban/rural surface heterogeneities during convective conditions. Quart. J. Roy. Meteor. Soc., 135, 1266-1276, doi:10.1002/qj.446.

Changnon, D., M. Sandstrom, and C. Schaffer, 2003: Relating changes in agricultural practices to increasing dew points in extreme Chicago heat waves. Climate Res., 24, 243-254, doi:10.3354/cr024243.

Chaves, M. M., and Coauthors, 2002: How plants cope with water stress in the field? Photosynthesis and growth. Ann. Bot. (London, U.K.), 89, 907-916, doi:10.1093/aob/mcf105.

Cohen, B., 2006: Urbanization in developing countries: Current trends, future projections, and key challenges for sustainability. Technol. Soc., 28 (1-2), 63-80, doi:10.1016/j.techsoc.2005.10.005.

Cohen, J. E., 2003: Human population: The next half century. Science, 302, 1172-1175, doi:10.1126/science.1088665.

Cornic, G., and A. Massacci, 1996: Leaf photosynthesis under drought stress. Photosynthesis and the Environment, N. Baker, Ed., Springer, 347-366.

Dousset, B., F. Gourmelon, K. Laaidi, A. Zeghnoun, E. Giraudet, P. Bretin, E. Mauri, and S. Vandentorren, 2011: Satellite monitoring of summer heat waves in the Paris metropolitan area. Int. J. Climatol., 31, 313-323, doi:10.1002/joc.2222.

Eliasson, I., and B. Holmer, 1990: Urban heat-island circulation in Goteborg, Sweden. Theor. Appl. Climatol., 42, 187-196, doi:10.1007/BF00866874.

Fischer, E. M., S. I. Seneviratne, D. Lüthi, and C. Schär, 2007: Contribution of land-atmosphere coupling to recent European summer heat waves. Geophys. Res. Lett., 34, L06707, doi:10.1029/2006GL029068.

— K. K. W. Oleson, and D. M. Lawrence, 2012: Contrasting urban and rural heat stress responses to climate change. Geophys. Res. Lett., 39, L03705, doi:10.1029/2011GL050576.

Haeger-Eugensson, M., and B. Holmer, 1999: Advection caused by the urban heat island circulation as a regulating factor on the nocturnal urban heat island. Int. J. Climatol., 19, 975-988, doi:10.1002/ (SICI)1097-0088(199907)19:9<975::AID-JOC399>3.0.CO;2-J.

Holmer, B., and I. Eliasson, 1999: Urban-rural vapour pressure differences and their role in the development of urban heat islands. Int. J. Climatol., 19, 989-1009, doi:10.1002/ (SICI)1097-0088(199907)19:9<989::AID-JOC410>3.0.CO;2-1.

Hu, L., and N. A. Brunsell, 2015: A new perspective to assess the urban heat island through remotely sensed atmospheric profiles. Remote Sens. Environ., 158, 393-406, doi:10.1016/ j.rse.2014.10.022.

Kalkstein, L. S., and J. S. Greene, 1997: An evaluation of climate/ mortality relationships in large U.S. cities and the possible impacts of a climate change. Environ. Health Perspect., 105, 84-93. [Available online at http://www.ncbi.nlm.nih.gov/pmc/ articles/PMC1469832/.]

Klinenberg, E., 2002: Heat Wave: A Social Autopsy of Disaster in Chicago. University of Chicago Press, 328 pp.

Kohonen, T., 1990: The self-organizing map. Proc. IEEE, 78, 14641480, doi:10.1109/5.58325.

Kolokotroni, M., and R. Giridharan, 2008: Urban heat island intensity in London: An investigation of the impact of physical characteristics on changes in outdoor air temperature during summer. Sol. Energy, 82, 986-998, doi:10.1016/ j.solener.2008.05.004.
Kunkel, K. E., S. A. Changnon, B. C. Reinke, and R. W. Arritt, 1996: The July 1995 heat wave in the Midwest: A climatic perspective and critical weather factors. Bull. Amer. Meteor. Soc., 77, 1507-1518, doi:10.1175/1520-0477(1996)077<1507: TJHWIT $>2.0 . \mathrm{CO} ; 2$.

Kuttler, W., S. Weber, J. Schonnefeld, and A. Hesselschwerdt, 2007: Urban/rural atmospheric water vapour pressure differences and urban moisture excess in Krefeld, Germany. Int. J. Climatol., 27, 2005-2015, doi:10.1002/joc.1558.

Lagouarde, J.-P., P. Moreau, M. Irvine, J.-M. Bonnefond, J. A. Voogt, and F. Solliec, 2004: Airborne experimental measurements of the angular variations in surface temperature over urban areas: Case study of Marseille (France). Remote Sens. Environ., 93, 443-462, doi:10.1016/j.rse.2003.12.011.

Lee, D. O., 1991: Urban-rural humidity differences in London. Int. J. Climatol., 11, 577-582, doi:10.1002/joc.3370110509.

Li, D., and E. Bou-Zeid, 2013: Synergistic interactions between urban heat islands and heat waves: The impact in cities is larger than the sum of its parts. J. Appl. Meteor. Climatol., 52 , 2051-2064, doi:10.1175/JAMC-D-13-02.1.

Livezey, R. E., and R. Tinker, 1996: Some meteorological, climatological, and microclimatological considerations of the severe U.S. heat wave of mid-July 1995. Bull. Amer. Meteor. Soc., 77, 2043-2054, doi:10.1175/1520-0477(1996)077<2043: SMCAMC $>2.0 . C O ; 2$.

Mayer, H., A. Matzarakis, and M. G. Iziomon, 2003: Spatio-temporal variability of moisture conditions within the urban canopy layer. Theor. Appl. Climatol., 76 (3-4), 165-179, doi:10.1007/ s00704-003-0010-y.

McCarthy, M. P., M. J. Best, and R. A. Betts, 2010: Climate change in cities due to global warming and urban effects. Geophys. Res. Lett., 37, L09705, doi:10.1029/2010GL042845.

McGeehin, M. A., and M. Mirabelli, 2001: The potential impacts of climate variability and change on temperaturerelated morbidity and mortality in the United States. Environ. Health Perspect., 109 (Suppl.), 185-189, doi:10.2307/ 3435008 .

Meehl, G. A., and C. Tebaldi, 2004: More intense, more frequent, and longer lasting heat waves in the 21 st century. Science, $\mathbf{3 0 5}$, 994-997, doi:10.1126/science.1098704.

NOAA/NCDC, 2001: Integrated surface global hourly data, DSI3505. NOAA/National Climatic Data Center. Subset used: June-August 2003-13, accessed December 2014. [Available online at https://data.noaa.gov/dataset/integrated-surfaceglobal-hourly-data.]

Oke, T. R., 1982: The energetic basis of the urban heat island. Quart. J. Roy. Meteor. Soc., 108, 1-24, doi:10.1002/ qj. 49710845502 .

- 1995: The heat island of the urban boundary layer: Characteristics, causes and effects. Wind Climate in Cities, J. E. Cermak et al., Eds., Springer, 81-107, doi:10.1007/ 978-94-017-3686-2_5.

— , G. T. Johnson, D. G. Steyn, and I. D. Watson, 1991: Simulation of surface urban heat islands under "ideal" conditions at night. Part 2: Diagnosis of causation. Bound.-Layer Meteor., 56, 339-358, doi:10.1007/BF00119211.

Oleson, K. W., A. Monaghan, O. Wilhelmi, M. Barlage, N. Brunsell, J. Feddema, L. Hu, and D. F. Steinhoff, 2015: Interactions between urbanization, heat stress, and climate change. Climatic Change, 129 (3-4), 525-541, doi:10.1007/ s10584-013-0936-8.

O'Neill, M. S., and K. L. Ebi, 2009: Temperature extremes and health: Impacts of climate variability and change in the United 
States. J. Occup. Environ. Med., 51, 13-25, doi:10.1097/ JOM.0b013e318173e122.

Patz, J. A., D. Campbell-Lendrum, T. Holloway, and J. A. Foley, 2005: Impact of regional climate change on human health. Nature, 438, 310-317, doi:10.1038/nature04188.

Peng, R. D., J. F. Bobb, C. Tebaldi, L. McDaniel, M. L. Bell, and F. Dominici, 2011: Toward a quantitative estimate of future heat wave mortality under global climate change. Environ. Health Perspect., 119, 701-706, doi:10.1289/ehp.1002430.

Richards, K., 2005: Urban and rural dewfall, surface moisture, and associated canopy-level air temperature and humidity measurements for Vancouver, Canada. Bound.-Layer Meteor., 114, 143-163, doi:10.1007/s10546-004-8947-7.

Rizwan, A. M., L. Y. C. Dennis, and C. Liu, 2008: A review on the generation, determination and mitigation of urban heat island. J. Environ. Sci., 20, 120-128, doi:10.1016/S1001-0742(08)60019-4.

Robine, J.-M., S. L. K. Cheung, S. Le Roy, H. Van Oyen, C. Griffiths, J.-P. Michel, and F. R. Herrmann, 2008: Death toll exceeded 70,000 in Europe during the summer of 2003. C. $R$ Biol., 331, 171-178, doi:10.1016/j.crvi.2007.12.001.

Runnalls, K. E., and T. R. Oke, 2000: Dynamics and controls of the near-surface heat island of Vancouver, British Columbia. Phys. Geogr., 21, 283-304, doi:10.1080/02723646.2000.10642711.

Sarrat, C., A. Lemonsu, V. Masson, and D. Guedalia, 2006: Impact of urban heat island on regional atmospheric pollution. Atmos. Environ., 40, 1743-1758, doi:10.1016/j.atmosenv.2005.11.037.

Schneider, A., M. A. Friedl, and D. Potere, 2009: A new map of global urban extent from MODIS satellite data. Environ. Res. Lett., 4, 044003, doi:10.1088/1748-9326/4/4/044003.
Seemann, S. W., J. Li, W. P. Menzel, and L. E. Gumley, 2003: Operational retrieval of atmospheric temperature, moisture, and ozone from MODIS infrared radiances. J. Appl. Meteor., 42, 1072-1091, doi:10.1175/1520-0450(2003)042<1072: OROATM>2.0.CO;2.

— E. Borbas, J. Li, W. Menzel, and L. Gumley, 2006: MODIS atmospheric profile retrieval. University of WisconsinMadison Algorithm Theoretical Basis Doc., 40 pp. [Available online at http://modis-atmos.gsfc.nasa.gov/_docs/ MOD07MYD07ATBDC005.pdf.]

Semenza, J. C., C. H. Rubin, K. H. Falter, J. D. Selanikio, W. D. Flanders, H. L. Howe, and J. L. Wilhelm, 1996: Heat-related deaths during the July 1995 heat wave in Chicago. N. Engl. J. Med., 335 (2), 84-90, doi:10.1056/NEJM199607113350203.

Voogt, J. A., and T. R. Oke, 2003: Thermal remote sensing of urban climates. Remote Sens. Environ., 86, 370-384, doi:10.1016/ S0034-4257(03)00079-8.

Whitman, S., G. Good, E. R. Donoghue, N. Benbow, W. Shou, and S. Mou, 1997: Mortality in Chicago attributed to the July 1995 heat wave. Amer. J. Public Health, 87, 1515-1518, doi:10.2105/ AJPH.87.9.1515.

World Health Organization, 2010: Hidden Cities: Unmasking and Overcoming Health Inequities in Urban Settings. WHO, 126 pp.

Yow, D. M., 2007: Urban heat islands: Observations, impacts, and adaptation. Geogr. Compass, 1, 1227-1251, doi:10.1111/ j.1749-8198.2007.00063.x.

Zhou, Y., and J. Shepherd, 2010: Atlanta's urban heat island under extreme heat conditions and potential mitigation strategies. Nat. Hazards, 52, 639-668, doi:10.1007/s11069-009-9406-z. 